\title{
A Linguagem como Experiência: Diálogos entre Merleau-Ponty e a Psicanálise
}

\author{
Thais Klein ${ }^{1}$ \\ Julio Vertzman ${ }^{1}$ \\ ${ }^{1}$ Universidade Federal do Rio de Janeiro, RJ, Brasil. \\ ${ }^{1}$ Universidade Federal do Rio de Janeiro, RJ, Brasil \\ Nelson Ernesto Coelho Junior ${ }^{2}$ \\ ${ }^{2}$ Universidade de São Paulo, SP, Brasil.
}

Resumo: A problemática da linguagem é cara ao campo psicanalítico - a exploração do domínio desvelado pela psicanálise engendrou uma série discussões em torno deste tema. No entanto, a ênfase reside principalmente no papel da linguagem na constituição do psiquismo, distanciando-se do domínio da linguística ou da perspectiva representacional da linguagem, este artigo busca enfatizar o seu uso. Através de um diálogo entre autores da psicanálise e a fenomenologia de Merleau-Ponty, circunscreve-se a linguagem enquanto uma dimensão da experiência, o que pressupõe não fornecer um papel central para seu advento no psiquismo, bem como não a elevar como condição necessária da emergência do sentido. Para tal, recorre-se à definição de certa noção de experiência na psicanálise que enfatiza uma indissociação entre corporeidade, sentido, tempo e mundo. Nesse contexto, a linguagem enquanto uma dimensão da experiência está necessariamente articulada a estes elementos - questão que abre um campo de discussão importante para a clínica psicanalítica.

Palavras-chave: Psicanálise, Linguagem, Fenomenologia, Experiência.

\section{Language as Experience: Dialogues between Merleau-Ponty and Psychoanalysis}

\begin{abstract}
The matter of language is important to the psychoanalytic field - the exploration of such domain unveiled by psychoanalysis has generated a series of debates around this subject. However, the emphasis lies mainly on the role of language in the constitution of the psyche. While distancing itself from the domain of linguistics and the representational perspective of language, this paper approaches it emphasizing its use. Through a dialogue between authors of psychoanalysis and the phenomenology of Merleau-Ponty, language is considered a dimension of experience, which presupposes it not to provide a central role for its advent in the psyche, as well as to not elevate it as a necessary condition to the emergence of meaning. The definition of a certain notion of experience emphasizes a lack of dissociation between corporeity, meaning, time and world. Language as a dimension of experience is necessarily articulated to these elements - a question that opens up an important field of discussion for psychoanalytic clinics.
\end{abstract}

Keywords: Psychoanalysis, Language, Phenomenology, Experience. 


\title{
El Lenguaje como Experiencia: Diálogos entre Merleau-Ponty y el Psicoanálisis
}

\begin{abstract}
Resumen: La problemática del lenguaje es importante al campo psicoanalítico, puesto que la explotación del dominio desvelado por el psicoanálisis produjo una serie de discusiones en torno a este tema. Sin embargo, el énfasis reside principalmente en el papel del lenguaje en la constitución del psiquismo. Distanciándose del dominio de la lingüística o de la perspectiva representacional del lenguaje, este artículo busca enfatizar su uso. Con base en el diálogo entre autores del psicoanálisis y la fenomenología de Merleau-Ponty, se circunscribe el lenguaje a una dimensión de la experiencia, lo que presupone no establecer un papel central para su advenimiento en el psiquismo, así como no elevarla a la condición necesaria a la emergencia de sentido. La definición de cierta noción de experiencia enfatiza una indisociación entre corporeidad, sentido, tiempo y mundo. El lenguaje mientras una dimensión de la experiencia está necesariamente articulada a estos elementos, una cuestión que abre una importante discusión para la clínica psicoanalítica.
\end{abstract}

Palabras clave: Psicoanálisis, Lenguaje, Fenomenología, Experiencia.

"Como surpreender, adivinhar, por detrás do silêncio, cada grão de som?"

(Guimarães Rosa, 1954, p. 120)

A linguagem, para a psicanálise, consiste em uma problemática vasta que marca sua história - pode-se afirmar que a exploração do domínio descoberto pela psicanálise abriu um campo de discussão em torno deste tema. O tratamento analítico é delineado de saída como a cura pela fala, destacando o papel da possibilidade de associar, ou seja, de articular representações palavras às representações coisas que caracterizam o sistema inconsciente. Conforme aponta Green (1984), muito embora na segunda tópica freudiana abra-se espaço para uma complexificação da concepção de linguagem - deixando de articulá-la apenas aos seus representantes - Freud nunca escreveu uma teoria própria sobre a linguagem. Pode-se simplesmente deduzir de seu pensamento uma teoria da linguagem ou propor uma leitura da obra freudiana articulada a questões trazidas pela linguística (como o fez Lacan). No entanto, esta problemática é bastante delicada ao ponto de Green (1984) afirmar que "a psicanálise adoraria poder dispensar de ter que dar um estatuto sobre o lugar - isto é, a tópica -, a função - isto é, a dinâmica - e enfim o modo de ação - a economia da linguagem na prática e na teoria psicanalíticas" (pp. 23-24). Pode-se dizer que muito embora esta questão tenha sido bastante discutida no campo analítico, a preocupação em torno desta temática reside principalmente na relação entre “a linguagem e 'processos internos'” (Green, 1984, p. 23). Isto é, a questão localiza-se prioritariamente em enfatizar como a linguagem se inscreve e constitui o psiquismo. Todavia, seguindo as indicações de Ogden (2005), a clínica psicanalítica nos exige abordar esta problemática de outra perspectiva. Recorrendo a uma articulação com a literatura, Ogden (2005) destaca que esta não se reduz à possibilidade de descrever a experiência humana - um romance não seria uma visão particular de um sujeito sobre o mundo - mas permitiria criar uma experiência entre o escritor e o leitor. Da mesma forma, a psicanálise mais do que procura os sentidos velados por trás do discurso daquele que está sendo ouvido: trata de enfatizar o modo pelo qual se diz e os efeitos criados pela fala no setting analítico ${ }^{1}$. Diante desse quadro, pretende-se abordar a questão da linguagem na psicanálise enfatizando o seu uso, mais precisamente seu estatuto de uma dimensão da experiência. Não nos propomos, portanto, a adentrar no terreno pantanoso do papel da linguagem na constituição

\footnotetext{
${ }^{1}$ Mais do que setting analítico, aqui seria preciso recorrer ao conceito de terceiro analítico de Ogden (1994). Muito embora não faça parte do escopo deste artigo um maior aprofundamento nesta questão, cabe indicar que se trata de um "terceiro sujeito com uma vida própria, gerada pelo par analítico e mantido em tensão dialética com a existência do paciente e do analista, como indivíduos separados" (Ogden, 1994, pp. 11-12).
} 
do sujeito, fazendo uma sorte de percurso histórico das diferentes concepções em teorias distintas ${ }^{2}$. O objetivo é de circunscrever a linguagem enquanto experiência, o que pressupõe não fornecer um papel central para o advento da linguagem no psiquismo, bem como não elevar este campo à condição necessária da emergência do sentido. Ao destacar a linguagem como uma dimensão da experiência, não pretendemos explicar, decompor, deduzir ou operar com ela, mas compreendê-la desde dentro como ato de expressão. Nesse âmbito, faz-se, portanto, necessário conceitualizar mais precisamente certa noção de experiência em psicanálise para versar sobre a questão do sentido, da linguagem e de suas repercussões na clínica psicanalítica em seguida. Para tal, pretende-se traçar um diálogo entre a fenomenologia (mais especificamente o pensamento merleau-pontyano) e a psicanálise.

\section{A experiência na psicanálise}

No campo psicanalítico, muitas vezes, somos impelidos a iniciar uma pesquisa a partir das considerações de Freud sobre o assunto. Como bons seguidores do pai da psicanálise, a metodologia de pesquisa é quase uma regra: iniciamos com um estudo aprofundado na obra freudiana para, em seguida, tecer as consequências, desdobramentos e, por fim, aproximar ou, nos melhores casos, apresentar contribuições para a questão. Muito embora esta "fórmula" possa empobrecer ou enrijecer a pesquisa em psicanálise, não é mera coincidência que ela se repita. A obra freudiana, além de base de todo o aparato psicanalítico, comporta uma pluralidade que exige um constante retorno de leitura dos textos. Desta perspectiva, faz-se importante pincelar as diferentes possibilidades de articulação entre experiência, sentido e significação nos textos de Freud.

Quando se trata de experiência, a primeira discussão importante é a da experiência primária de satisfação (Befriedigungserlebnis) ${ }^{3}$ descrita por Freud no "Projeto para uma psicologia científica".
(Freud, 1895[1950]/1977). Grosso modo, a experiência de satisfação diz respeito a um esquema que marca constituição do aparato psíquico articulando-a com uma dimensão intensiva e a presença de um Nebenmensch, palavra que Davi-Ménard (2000) sugere traduzir por "homem ao lado". Mas qual seria o estatuto da experiência e sua articulação com o sentido neste caso? Trata-se de uma experiência solipsista e subjetiva que tem como correlato a inscrição de representações no psiquismo? O "homem ao lado" (Nebenmensch) está lá, pronto para ser conhecido objetivamente pelo bebê? A experiência de satisfação, posto que articula um "homem ao lado" (correspondente ao mundo externo) e um bebê (que sofre das exigências da vida) poderia ser pensada a partir de uma perspectiva objetivista.

O "objetivismo", sumariamente, é um termo que designa certo tipo de atitude epistemológica na qual os objetos são como são; isto é, eles se situam no mundo externo (Simanke, 2016). A experiência desta perspectiva tem um lugar específico, a saber, a mente (ou a "subjetividade") dos observadores. A relação com o mundo externo, que existe de forma independente, é decorrente de certa atitude ou função intencional - mesmo inconsciente - protagonizada pelo sujeito. Sob este viés, o sujeito precisa conhecer o mundo que está lá, aguardando para ser conhecido. Ora, o bebê que sofre das exigências da vida pode ser considerado um "ente" separado do mundo exterior - este consolidado pelo homem ao lado que vem lhe dar assistência - que somente a partir das exigências da vida (espécie de motivação), terá contato com este mundo externo.

A experiência de satisfação, quando abordada desta forma, seria uma experiência subjetiva do bebê que inaugura o seu contato com o mundo externo. Seguindo as indicações de Simanke (2016), deste ângulo, atribui-se um suposto objetivismo à teoria freudiana que consiste em "uma concepção ingênua sobre a natureza do objeto psíquico e sobre a natureza da relação sujeito-objeto" (p. 89).

\footnotetext{
${ }^{2}$ De certa forma, Green (1984) o faz quando se propõe a falar sobre a linguagem na psicanálise.

${ }^{3}$ A expressão utilizada por Freud é composta pela palavra Erlebnis. Em alemão existem ao menos duas palavras que no português podem ser traduzidas por experiência: Erfahrung e Erlebnis. O verbo fahren, que compõe a primeira expressão, significa viajar, ir (com algum meio de transporte). O substantivo Leben significa vida e o verbo erleben pode ser traduzido por "vivenciar". Por exemplo, quando em alemão pretendemos falar, "aquela foi uma experiência incrível", a palavra mais correta a ser usada é Erlebnis, e não Erfahrung. Talvez por isso a primeira expressão tenha sido traduzida para o português muitas vezes como "vivência", pois denota mais o sentido de experienciar do que de aprender. Optamos por traduzir Erlebnis por experiência. Alguns autores na filosofia privilegiam o uso da palavra Erfahrung na medida em que esta se afasta da ideia de uma interioridade subjetiva, de algo privado, para se aproximar da noção de travessia.
} 
Partindo de uma leitura que atribui uma posição objetivista a Freud, o problema do sentido ou da significação surge inicialmente como tributário de uma operação de nomeação, ou seja, o universo do sentido seria consequência da atribuição de nomes às coisas, em que palavras e objetos se associassem uns aos outros na mente e na experiência dos sujeitos (Gabbi, 2005). O sentido não estaria articulado à experiência em si, mas decorreria da possibilidade de representação, seja ela coisa, seja palavra. O objetivismo se manifestaria exemplarmente na concepção freudiana da linguagem, segundo a qual a significação teria uma origem perfeitamente extralinguística: ela proviria de um objeto externo ao sujeito e externo à linguagem, subsistindo e podendo ser concebido independentemente de sua relação com ambos, que, ao se associar contingentemente com uma ideia de palavra, confere-lhe significação.

Diante desse quadro, poderíamos prosseguir esta exposição enfatizando outras perspectivas da obra freudiana que permitiriam leituras distintas sobre o papel da significação e, sobretudo, da noção de experiência. No entanto, é preciso destacar que outros caminhos foram abertos para articular melhor este tema a partir de Freud. As controvérsias entre Anna Freud e Melanie Klein possibilitaram pensar em uma nova direção para se discutir a experiência e a significação. Um ponto nevrálgico desta discussão reside justamente na definição e no papel atribuído à fantasia a partir do pensamento kleiniano.

Neste âmbito, as considerações de Isaacs (1943/1998), autora que sistematiza com maior complexidade a noção de fantasia na literatura kleiniana, subsidiam uma revisão profunda das metáforas psicanalíticas centrais sobre a atividade da mente (Souza, 2000). Trata-se da substituição de um modelo estrutural predominante em Freud por um modelo de mundo interno concebido em termos de relações fantasiadas de objeto interno (Ogden,
2014). Isto porque Isaacs (1943/1998) concebe todos os processos mentais e mecanismos mentais como formas inconscientes de fantasiar.

A fantasia, deste ponto de vista, não é produto das instâncias psíquicas ou de significações, ela mesma é um processo de significação. Neste âmbito, os mecanismos e operações mentais não são delineados a partir de instâncias "impessoais, similares à produção de insulina por células especializadas do pâncreas em resposta a mudanças do nível de açúcar no sangue" (Ogden, 2014, p. 65), eles devem ser vistos como tipos específicos de fantasiar. Ou seja, os mecanismos psíquicos são eles mesmos experiências psíquicas, expressões significativas e não reações diante de significações (Isaacs, 1943/1998).

Segundo Souza (2000), detalhando os encontros e desencontros entre Brierley e Heiman - um capítulo das controvérsias entre os anna-freudianos e os kleinianos -, o que está em jogo nas concepções de Heiman (e, logo, dos kleinianos) diz respeito à possibilidade abordar a causalidade psíquica, não como articulada a processos ou mecanismos psíquicos desprovidos de sentido, mas entendida ela mesma como experiencial ${ }^{4}$. Enquanto em Freud as pulsões governam o psiquismo sem estarem diretamente ali presente - o estão apenas por meio de seus representantes -, a pulsão não aparece por intermédio de uma representação com esta concepção particular de fantasia, mas indiretamente, no plano primário das sensações (Petot, 1988).

Logo, o conceito de fantasia articulado à noção de pulsão de Klein e Isaacs, ainda que resista a um deslocamento total do subjetivismo implicado pela perspectiva representacional tributária da concepção clássica de sujeito da representação, engendra uma possibilidade de saída do solipsismo herdeiro desta tradição ${ }^{5}$. Desta forma, valoriza-se a "ideia de experiência psíquica em detrimento da noção de mecanismo psíquico, valorização esta que tem vastas consequências para a psicanálise contemporânea"

\footnotetext{
${ }^{4}$ Esta questão é epistemológica e ontológica, posto que ao afirmar explicitamente o sentido como cerne irredutível de todo o psiquismo, coloca-se questões para o projeto, defendido por Freud diversas vezes, de inserir a psicanálise no campo das ciências da natureza. O debate em torno do status metapsicológico e ontológico da teoria kleiniana é um assunto largamente discutido e controverso, inserindo-se no contexto de discussão em torno do lugar epistemológico da psicanálise. (Macckay, 1981; Souza, 2000)

${ }^{5}$ É importante destacar que Simanke (2005), em um artigo bastante interessante sobre a noção de representação na teoria freudiana, assinala que em Freud esta questão, ao se articular ao afeto e ao corpo, comporta uma dimensão que se distancia da concepção clássica de representação.
} 
(Souza, 2000, p. 5, grifo nosso). Logo, sob certo ponto de vista ${ }^{6}$, a teoria kleiniana abre espaço para o distanciamento da intenção de conhecer os mecanismos psíquicos (suas instâncias etc.) em uma linguagem objetiva e impessoal, possibilitando a descrição dos processos de sentido.

Trata-se do deslocamento da ênfase no significado dos pensamentos - o que pensamos - para o modo como pensamos, favorecendo uma aproximação entre os construtos metapsicológicos e as descrições clínicas (Macckay, 1981)7. Diante desse quadro, o autor se pergunta: "a teoria de Melanie Klein é melhor construída como uma teoria mecanicista do tipo freudiano, ou como uma fenomenologia?" (Macckay, 1981, p. 191). Muito embora não seja preciso traçar aqui as diferentes posições sobre esta questão (Macckay o faz bastante bem), é importante destacar que a possibilidade de colocar a pergunta desta perspectiva aponta para ao menos uma oportunidade de aproximação da experiência subjetiva engendrada pela teoria kleiniana ${ }^{9}$.

No entanto, destaca-se que não somente a fanta$\mathrm{sia}^{10}$, mas também a maneira como a problemática em torno da experiência subjetiva é abordada constituem uma questão central no que concerne à possibilidade de articular as considerações do campo kleiniano em certa noção de experiência. Isto porque a palavra "subjetiva" que acompanha "experiência" indica que essa perspectiva pode estar atrelada a uma experiência subjetiva (individual) ${ }^{11}$. Ou seja, a descrição da experiência que a teoria kleiniana possibilita através do enfoque nas significações psíquicas implica numa descrição marcada pela subjetividade entendida como interna e particular em contraposição a uma realidade externa ${ }^{12}$; pode-se, de certa forma, aproximá-la do subjetivismo filosófico ou mesmo do realismo ingênuo. Se referindo a esta questão, Green (1964) afirma que "este sistema comporta tanto, senão mais, germes idealistas que todos os outros desequilíbrios do pensamento freudiano" (p. 1045).

Neste contexto, Isaacs, segundo Ogden (2014), teria enriquecido a noção de fantasia de Klein - tratar-se-ia de uma personagem central na transição da era Freud-Klein para a era Winnicott-Bion - ao enfatizar a fantasia como uma interpretação subjetiva da experiência. Estes últimos preferiram propor como característica mínima do psíquico uma dimensão não pulsional da experiência anterior à experiência pulsional,

\footnotetext{
${ }^{6}$ De maneira curiosa, por outro lado, atribui-se com frequência uma concepção de pulsão próxima ao biológico que provém principalmente do caráter internalista de certos conceitos teóricos aos kleinianos. A crítica se dirige à impressão de que esta perspectiva teórica reduz o papel desempenhado pelo meio ambiente e acentua o fator inato da constituição pulsional para todo o desenvolvimento psíquico. A noção de identificação projetiva, que supostamente engendraria uma articulação entre a fantasia e os objetos, ocorre por vezes não propriamente entre o sujeito e o objeto, mas entre o sujeito e sua imagem - sua construção ou representação interna do inconsciente - do objeto.
}

${ }^{7}$ No entanto, Macckay (1981) aponta que a noção de fantasia tem uma dupla perspectiva em Klein: por vezes, é concebida como o meio real da experiência - ou seja, como expressão direta da pulsão e permeada de sentido -, em outros momentos, destacada em sua articulação à linguagem "estrutural" de Freud, isto é, relacionada a uma atividade egóica e até mesmo como algo passível se opor à realidade.

${ }^{8}$ Para o autor, uma visada fenomenológica prescindiria, de certa forma, da metapsicologia. Ao nosso ver, não é preciso - ou talvez não seja possível - excluir a metapsicologia de uma perspectiva que enfatiza a experiência na psicanálise. Não colocaríamos, portanto, a pergunta da mesma forma do autor, muito embora enfatizemos que a possibilidade de colocar esta pergunta desta forma indica certa questão.

${ }^{9}$ Cabe destacar que Merleau-Ponty se interessou bastante pela obra de Klein, principalmente ao longo de sua passagem pela Sorbonne, sendo o primeiro tradutor desta autora para a língua francesa. Green (1964) salienta que a dimensão da castração é trocada pelo despedaçamento em Klein: na relação triangular (pai, mãe, filho), privilegia-se o estudo da relação dual (mãe e filho) e contrapõe-se uma hegemonia maternal ilustrada pela imagem da mãe fálica onipotente à posição dominante do pai como detentor do falo.

${ }^{10}$ Poderíamos também ressaltar a noção de realidade na obra de Klein. Esta, muitas vezes, reduz-se a um conceito que se aproxima de uma espécie de "realismo ingênuo", isto é, a realidade é amiúde concebida como estática, como o lado de "fora" que está pronto para ser conhecida.

${ }^{11}$ Todavia, é preciso destacar, baseando-se nas considerações de Ogden (2014), que as dimensões de significação e expressão enfatizadas nas concepções de Isaacs (1943/1998) sobre a fantasia engendram a possibilidade de vincular o início do psiquismo com a experiência da intersubjetividade, posto que a fantasia pode não ser considerada solipsista quando articulada ao mecanismo de identificação projetiva. No entanto, a noção de "realidade" na obra de Klein é pouco tematizada e torna-se eventualmente próxima a um realismo ingênuo, como aponta Green (1964).

${ }^{12}$ Faz-se importante destacar que esta questão pode ser pensada a partir de outras perspectivas: Angelino (2005), por exemplo, propõe uma articulação entre as considerações de Merleau-Ponty sobre a noção de carne e as concepções de objeto em Klein no âmbito da posição esquizoparanoide, enfatizando uma dimensão intersubjetiva importante na obra desta. A autora procura destacar a noção de identificação projetiva no sentido de delinear a possibilidade de uma indissociação entre mundo externo e interno desde os primórdios do psiquismo na teoria kleiniana. De uma perspectiva oposta, Green (1964) aponta que a distinção entre sujeito e objeto, realidade psíquica interna e externa é praticamente inexistente em Klein. 
dimensão esta que se constituía como o terreno sobre o qual todo o psiquismo se enraíza (Souza, 2000).

Nossa hipótese é que a teoria winnicottiana, através da centralidade dada a uma certa noção de experiência, provoca um deslocamento do campo psicanalítico em relação às tradições idealistas e empiristas, abrindo espaço para outras perspectivas teórico-clínicas e principalmente para certa articulação entre experiência e sentido ${ }^{13}$. Concordamos com Naffah Neto (2005), segundo o qual a definição mais sucinta que se poderia dar da obra winnicottiana é a de uma psicanálise da experiência humana em seu devir próprio. Afinal, como podemos definir a noção de experiência na psicanálise a partir do campo aberto desde a teoria kleiniana, mas consolidado por Winnicott?

\section{Winnicott e Merleau-Ponty: certa noção de experiência}

Aqueles que estão habituados à obra deWinnicott notam, e ele mesmo o confessa, o modo não sistematizado de transmitir suas considerações. É evidente que não encontramos nos seus textos uma definição precisa do que é experiência e de autores que possam colaborar ou se contrapor a ela. Justamente por isso buscaremos interlocutores principalmente na fenomenologia para alavancar subsídios para melhor circunscrever esta noção. Talvez, assim como Ogden (2001/2013), chama a atenção para a sonoridade das palavras escolhidas por Winnicott e os benefícios de uma leitura em voz alta, seja possivelmente o ato de ler a obra winnicottiana e, sobretudo, a situação clínica que podem nos fazer de fato acessá-la. Isto porque muito embora a compreensão intelectual possa ser algo que passe pela zona da experiência, esta não se restringe a ela. Conforme aponta Bezerra (2008), "há sempre muito mais na totalidade da experiência do que aquilo que somos capazes de aprender linguisticamente" (p. 224).

Uma das assertivas mais precisas, mas não por isso clara, que encontramos na obra winnicottiana sobre a experiência está em uma carta de Winnicott a Money Kyrle: "a experiência é um trafegar constante na ilusão, uma repetida procura da interação entre a criatividade e aquilo que o mundo tem a oferecer" (Winnicott 1952/2005, p. 53, grifo nosso). As palavras grifadas apontam para a necessidade de pensar a experiência não como uma questão estática (trafegar constante) e muito menos como algo que se dá subjetivamente (interação). A chave para melhor definir uma noção de experiência que não se reduza nem a uma perspectiva subjetiva - "a experiência acontece no meu interior" -, nem objetiva - "a experiência diz respeito ao meu encontro com o mundo que está do lado de fora" - é justamente procurar subsídios em um diálogo com a fenomenologia.

No prefácio de Fenomenologia da percepção, Merleau-Ponty (1945/2011) enfatiza o propósito de Husserl de retorno às coisas. Nas suas palavras: "retornar às coisas mesmas é retornar a este mundo anterior ao conhecimento" (p. 4). A experiência, nesse sentido, não está destacada no mundo, ou seja, não pode ser concebida como interna ou apenas relacional, ela "não provém de meus antecedentes, de meu ambiente físico e social, ela caminha em direção a eles e os sustenta" (pp. 3-4). Logo, é preciso conceber a experiência como prescindindo de uma fronteira bem delineada entre o eu e o mundo de saída. Para Merleau-Ponty (1945/2011) “a verdade não 'habita' apenas o 'homem interior', ou antes, não existe homem interior, o homem está no mundo, é no mundo que ele se conhece" (p. 6). Mas como definir o que é o mundo desta perspectiva? O mundo é justamente "aquilo que nós percebemos” (Merleau-Ponty, 1945/2011, p. 14). A percepção, para Merleau-Ponty, ocupa um lugar entre o objetivo e o subjetivo, entre aquele que percebe e o mundo percebido - é, sobretudo, o lugar da ambiguidade e, por que não, do paradoxo. Nesse sentido, assim como não é possível falar do percebido sem aquele que percebe, não se pode falar daquele que tem uma experiência e daquilo que é experienciado separadamente. A expressão "ter uma experiência" já coloca problemas de saída, pois a experiência não pressupõe um sujeito que a possui.

Esta problemática fica mais evidente quando se adiciona outro aspecto à noção de experiência. Uma segunda questão decorrente destas considerações implica na impossibilidade de afirmar que a experiência diz respeito à fundação do aparato psíquico, como muitas vezes estamos acostumados em psicanálise; na esteira do pensamento de Winnicott, a experiência

\footnotetext{
${ }^{13}$ Todavia, não concebemos este deslocamento como uma espécie de mudança de paradigma. Isto porque, conforme procuramos demostrar, além de vir na esteira de outros teóricos ao longo da história da psicanálise, esta questão pode também ganhar leituras distintas tanto em Freud quanto em outros autores.
} 
se articula a uma dualidade múltipla que engloba inevitavelmente o corpo e, mais especificamente, o soma. Este não é apenas o corpo biológico, a ideia de soma diz respeito, sobretudo, a um corpo vivo que possui a sua vitalidade como característica principal e é, por isso, capaz de se mover, de entrar em repouso, de respirar e assim por diante. Nesse sentido, o soma na obra de Winnicott está intrinsecamente ligado às interações como mundo. Em uma direção parecida, para Merleau-Ponty é por meio do corpo que age que se é o tempo e se tem um mundo - entendido como o conjunto de aspectos do universo que afetam o corpo e ao qual ele se dirige. A noção de carne ${ }^{14}$ assinala justamente no plano ontológico a interdependência do corpo, mundo e tempo, muito embora não caiba no escopo deste artigo um maior aprofundamento

O que nos interessa aqui é mais precisamente o fato de que o corpo tanto para Winnicott com a ideia de soma, quanto para Merleau-Ponty ${ }^{15}$, é "nosso ancoradouro no mundo" (Merleau-Ponty, 1945/2011, p. 171). Não se pode dizer que se tem um corpo, mas se é um corpo. Desta ótica, a experiência envolve necessariamente a corporeidade ${ }^{16} \mathrm{ou}$, mais precisamente, a experiência é corporal. Nossa primeira hipótese, portanto, supõe que corporeidade e experiência sejam indissociáveis.

Vinculada à esta questão, é preciso retomar a expressão "trafegar constante" utilizada por Winnicott para definir a experiência. Ora, deste modo não é possível conceber a experiência como algo que se dá fora do tempo ou a partir de um tempo serial, cronológico ou mesmo marcado por cortes. O verbo no infinitivo "trafegar" indica que a experiência é algo que se dá em relação a um tempo que dura, se desenrola, permanece. O tempo não se dobra a um espectador absoluto, ele não é para alguém, mas é alguém. Conforme aponta Merleau-Ponty (1945/2011), "somos obrigados a fazer-nos do tempo e do sujeito uma concepção tal que eles se comuniquem do interior" (p. 549).

É somente por uma experiência que o tempo e o sujeito são. Deste modo, considera-se o tempo não para "tirar as consequências de uma concepção preestabelecida da subjetividade" (MerleauPonty, 1945/2011, p. 550), mas para concebê-lo como a matéria de que o sujeito é feito. O tempo, deste modo, compõe a dobra da corporeidade e do mundo - o passado, o presente e o futuro estão no mundo (Merleau-Ponty, 1945/2011). Não se trata do mundo concebido como objetivo, mas do mundo experienciado, posto que "o tempo não é uma linha, mas uma rede de intencionalidades" (MerleauPonty, 1945/2011, p. 558). Muito embora não caiba no escopo deste artigo um maior aprofundamento nesta concepção de tempo, faz-se importante destacar que nossa segunda hipótese, portanto, supõe que tempo e experiência sejam indissociáveis.

Outra consideração importante no que concerne à definição de certa noção de experiência, justamente a questão central deste artigo, diz respeito a sua articulação ao sentido. A discussão em torno do "sentido" não é simples, pois é preciso explicitar melhor o que se quer dizer quando se refere ao sentido, posto que sua polissemia é evidente. Bezerra (2001) destaca algumas significações distintas para esta palavra: pode-se referir à direção, rumo, ou ao bom senso, razoabilidade, aspectos, vertentes ou mesmo conceituação. Esta pluralidade também aparece quando se discute a articulação entre sentido e experiência - a maneira como se delimita a noção de sentido reflete os alcances que este termo pode abarcar. Neste ponto, um problema central diz respeito à relação entre sentido e linguagem: a linguagem seria uma condição necessária para

\footnotetext{
${ }^{14}$ Nas palavras de Merleau-Ponty (1964/2014): “carne não é matéria, não é espírito, não é substância. Seria preciso, para designá-la, o velho termo 'elemento', no sentido em que era empregado para falar-se da água, do ar, da terra e do fogo, isto é, no sentido de uma coisa geral, a meio caminho entre o indivíduo espaço-temporal e a ideia, espécie de princípio encarnado que importa um estilo de ser em todos os lugares onde se encontra uma parcela sua" (pp. 183-184).

${ }^{15}$ É interessante notar que no livro póstumo e inacabado O visível e o invisível, Merleau-Ponty (1964/2014) afirma que "fazer uma psicanálise da Natureza, é a carne, a mãe" (p. 321). É bastante tentador fazer uma analogia direta entre as proposições de Winnicott sobre a unidade não homogênea que se forma entre mãe e bebê nos primórdios e esta perspectiva desvelada por Merleau-Ponty - deixemos, todavia, esta questão para um maior aprofundamento ao longo deste artigo.

${ }^{16}$ A este respeito, é importante destacar a distinção feita por Coelho (2010) entre corporeidade e corpo. Para o autor, a noção de corpo é marcada pela tradição que opõe corpo à mente e carrega a carga de suas posições na história de nossa cultura. Já por meio do conceito de corporeidade, pretende-se um deslocamento deste dualismo. O autor sugere a noção de corporeidade como uma alternativa à clássica oposição corpo-mente (Coelho, 2010). Corporeidade inclui também a dimensão e não se reduz ao corpo biológico ou particular, nas suas palavras: "a corporeidade é ao mesmo tempo interna e externa. É a presença irrecusável das pulsões e a abertura permanente para o mundo, para os outros" (Coelho, 2010, p. 56). Ainda seguindo as indicações do autor, talvez seja melhor falar de co-corporeidade, uma vez que esta destaca a corporeidade não como pertencente a um sujeito, mas intrinsecamente ligada ao mundo e a outas corporeidades.
} 
a possibilidade de sentido ou este seria autônomo em relação à linguagem? A discussão entre essas perspectivas é extensa e não cabe, no escopo deste escrito, um maior aprofundamento nos argumentos a favor ou contra cada uma das posições ${ }^{17}$. Muito embora concordemos com Bezerra (2001), ao afirmar que remeter ao sentido como algo sem correlação necessária com a linguagem implica em uma concepção mais ampla de sentido, não cremos que se trate apenas de uma questão semântica. Associar o sentido à certa noção de experiência na psicanálise nos faz conceber o tratamento analítico como a possibilidade de experienciar e não necessariamente como produção narrativa. Ogden (2005), conforme aprofundaremos adiante, assinala que uma fala ou certo discurso - tanto do analista quanto do analisando - pode estar sem vitalidade ou constituir uma espécie de imitação, inviabilizando a possibilidade de produzir qualquer efeito tanto naquele que fala quanto naquele que escuta.

Articulando a experiência artística ao sentido, Merleau-Ponty (1948/1996) afirma que "quando nos confrontamos com uma novela genuína, um poema uma pintura ou um filme, sabemos que um contato foi estabelecido com alguma coisa, que alguma coisa foi adquirida para os humanos" (p. 3). Merleau-Ponty (1948/1996) aponta que o sentido adquirido não pertence nem ao pensamento daquele que criou o trabalho, nem daquele que o percebe - esta perspectiva se aproxima bastante do comentário de Ogden sobre a literatura mencionado acima. Deste modo, o sentido não se restringe à linguagem e não diz respeito somente a algo que pertence ao sujeito ou ao mundo, mas está intimamente vinculado à experiência. Esta não revela um sentido que algo possui, mas "cria de um só golpe, com a constelação de dados, o sentido que os une - que não apenas descobre o sentido que eles têm, mas faz com que tenham sentido" (MerleauPonty, 1945/2011, p. 75). Logo, a experiência está grávida de sentido, ou melhor, é sentido. Nossa terceira hipótese supõe, portanto, que sentido e experiência sejam indissociáveis.
Antes de prosseguir na questão da linguagem enquanto uma dimensão da experiência, destacamos que tanto para Winnicott quanto para Merleau-Ponty a experiência em sua dimensão fundamental é, sobretudo, uma experiência pré-reflexiva sensorial, isto é, ela prescinde da reflexão. Na perspectiva de Winnicott (1971/1988), as considerações levantadas pelo autor no texto "Creativity and its origins" ("A criatividade e suas origens") sobre os elementos masculino e feminino são importantes para nossa argumentação. Enquanto o elemento masculino se relaciona com o fazer/ter, o elemento feminino diz respeito ao ser.

Apesar de não nos referirmos a uma lógica temporal cronológica, a experiência de ser é aquilo que possibilita a experiência de ter, isto é, possibilita que o elemento masculino seja experienciado. $\mathrm{O}$ verbo "ter" indica um sujeito e um objeto - "alguém tem algo" - "em contraste, o elemento feminino puro relaciona-se com o seio (ou com a mãe) no sentido de o bebê tornar-se o seio (ou a mãe), no sentido de que o objeto é o sujeito" (Winnicott, 1971/1988, p. 96, grifo nosso). A experiência de ser é, portanto, anterior ao processo de separação e diferenciação do sujeito/ objeto. O verbo "ser" comporta um soma indeterminado, sem fronteiras definidas ${ }^{18}$.

Diante desse quadro, muito embora não se trate de um dualismo inicial, não se pode dizer que os elementos tanto do soma do bebê quanto da mãe ou do mundo sejam homogêneos. A proposição do elemento feminino primário, na qual o bebê é o seio, só alcança inteligibilidade se o tornar-se for um movimento bidirecional sem ponto fixo de estabilização; a possibilidade de ser é definida por dois movimentos heterogêneos que se encontram, mas não se fundem $^{19}$. Pode-se aproximar esta concepção no campo da psicanálise às contribuições de Ogden (1989) sobre o assunto. $\mathrm{O}$ autor enfatiza um modo sensório que diz respeito à mais primitiva zona da experiência.

Em diálogo direto com Klein, Ogden (1989) propõe a posição-autística contígua (no original "autistic-position"; tradução nossa) descrita como uma

\footnotetext{
${ }^{17}$ Para um maior aprofundamento nesta temática, ver Costa (2001). Neste artigo, o autor traça alguns argumentos - tanto epistemológicos quanto no campo denominado por ele de "psicológico" (p. 201) -, demonstrando possíveis equívocos de uma perspectiva que considera a possibilidade de sentido desarticulado à linguagem.

${ }^{18}$ No âmbito da perspectiva winnicottiana, não se pode dizer que, de saída, há a mãe e o bebê, mas também não se trata de um estado de total indiferenciação; há uma presença complexa que comporta parceria e oposição. A perspectiva winnicottiana, ao menos em relação à dimensão da experiência de ser, se aproxima mais do que Coelho e Figueiredo (2012) designaram por "intersubjetividade transubjetiva”. Nas palavras dos autores: "trata-se, é evidente, de uma modalidade pré-subjetiva de existência" (p. 26).

${ }^{19}$ Ademais, conforme aponta Lannes (1997), é preciso enfatizar que a experiência de ser está intimamente articulada à dimensão temporal.
} 
experiência não reflexiva (anterior ao pensamento) e baseada na percepção (sensorial). A palavra "autística" aqui não designa uma concepção solipsista, mas marca a hipótese de limiares perenes em relação ao mundo, caracterizada principalmente pelas sensações. Não se trata de uma "experiência do bebê", mas de algo que está intimamente ligado ao mundo. Neste contexto, as noções de musicalidade, ritmo, toque, dentre outras, tornam-se os elementos centrais desta dimensão da experiência.

Porém na ótica de Merleau-Ponty (1960/1991), a experiência sensível é o "fundamento de direito" (p. 252) de todas as construções de conhecimento. Nas suas palavras: "todo o conhecimento, todo pensamento objetivo vive do facto inaugural de haver sentido, de haver possuído, com esta cor ou com o qualquer sensível que esteja em causa" (MerleauPonty, 1960/1991, p. 252). Marca-se assim o caráter primordial desta experiência, já que é somente a partir da percepção de uma outra sensibilidade (Empfindbarkeit) que se pode ter acesso a "um outro homem e um outro pensamento." (Merleau-Ponty, 1960/1991, p. 254). Muito embora esta experiência seja pré-reflexiva, ou seja, prescinda do pensamento, isto não quer dizer que ela é sem sentido. Conforme destacamos anteriormente, nossa hipótese pressupõe uma indissociação entre sentido, tempo, corpo, mundo no que concerne à experiência.

Para Merleau-Ponty (1945/2011), o sentido pertence aos objetos nem à consciência de um sujeito, isto é, não é algo interno que se apreende, nem ao externo que as coisas têm - o sentido emerge da percepção, da experiência pré-reflexiva. Desta forma, descarta-se a possibilidade de conceber de um lado a consciência, o sujeito (ou o bebê) e do outro lado o mundo, as coisas (ou a mãe), portadores do sentido. Nem sujeito nem objeto possuem sentidos próprios - esta dicotomia inclusive é tributária de um plano racional secundário. Seguindo as indicações de Coelho (2010), a noção de uma intencionalidade operante nos recoloca nessa zona de indistinção pré-reflexiva, onde a compreensão dos sentidos se estabelece sempre a partir de uma presença entrelaçada de corpo e mundo e da experiência humana da intercorporeidade.

O sentido, portanto, não é tributário de outro que o fornece, mas reside na experiência pré-reflexiva articulado ao elemento carne (corporeidade, mundo e tempo). Todavia, a experiência pré-reflexiva não constitui a única dimensã $0^{20}$ da experiência. Muito embora não caiba no escopo deste artigo descrever mais detalhadamente outras possíveis dimensões, certas questões articuladas à clínica psicanalítica nos incitam a abordar a problemática da linguagem apoiado em uma articulação à experiência.

\section{A linguagem como dimensão da experiência}

Diante desse quadro, pode-se dizer que a linguagem não abarca a totalidade da experiência, bem como não é a condição necessária para o advento do sentido. No entanto, seria impossível negar que a linguagem pode se articular à corporeidade, ao tempo, sentido e mundo. Discutir a linguagem sobre esta perspectiva consiste em um caminho espinhoso, posto que, conforme destacamos dantes, a linguagem na psicanálise é abordada principalmente a partir de concepções que enfatizam o seu papel na constituição do psiquismo. Ademais, nosso principal interlocutor no campo psicanalítico (Winnicott) não possui uma teoria clara sobre a linguagem ${ }^{21}$, o que nos instiga mais uma vez a buscar um diálogo direto com a filosofia de Merleau-Ponty.

Independentemente de não caber no escopo deste escrito um maior aprofundamento no percurso teórico de Merleau-Ponty em relação à linguagem $^{22}$, é importante destacar que esta questão retoma um dos objetivos que perpassa toda a sua obra, a saber: a busca de um caminho teórico que ultrapasse a divisão entre sujeito e mundo. Nas suas palavras: "procurando descrever o fenômeno da

\footnotetext{
${ }^{20}$ A palavra "dimensão" visa enfatizar outras possibilidades de manifestação da experiência (levando em conta sua articulação com a corporeidade, o tempo e o mundo). Porém não pretendemos assinalar uma temporalidade cronológica e um percurso predefinido entre as dimensões da experiência, mas uma possibilidade de coexistência entre elas.

${ }^{21}$ No entanto, certas considerações de Winnicott sobre a comunicação ou mesmo o silêncio poderiam contribuir enormemente para esta discussão. Deixamos esta questão indicada para um estudo futuro. Para situar melhor esta temática, ver Coelho \& Barone (2007) e Gomes (2017).

${ }^{22}$ A problemática da linguagem foi pouco tematizada nas duas primeiras obras: A Estrutura do Comportamento (Merleau-Ponty, 1942/1975) e Fenomenologia da Percepção (Merleau-Ponty,1945/2011). Este tema torna-se de maior interesse no final da década de 1950, quando além de alguns cursos no Collège de France, destaca-se o livro publicado postumamente em 1969 com o título A Prosa do Mundo (Merleau-Ponty, 1969/2002) - uma condensação desta obra já havia sido publicada em Sinais (Merleau-Ponty, 1960/1991) - nosso enfoque recairá, sobretudo, neste último texto.
} 
fala e o ato preciso de significação, teremos oportunidade de ultrapassar definitivamente a dicotomia clássica entre sujeito e objeto" (Merleau-Ponty, 1945/2011, p. 203). Se a articulação entre a linguagem e o sujeito fosse pensada a partir da noção de representação, jamais seria possível ultrapassar uma dicotomia entre sujeito e objeto, posto que esta remeteria a imagens verbais depositadas no psiquismo - concepção que se aproxima da teoria representacional da primeira tópica freudiana ${ }^{23}$.

É interessante notar que no VIe. Colloque de Bonneval (VI Colóquio de Bonneval) organizado por Henry Ey sobre o inconsciente (Ey, 1966), MerleauPonty deixa entrever seu incômodo em relação ao lugar que a linguagem ocupa na concepção do inconsciente: "algumas vezes experimento um mal-estar em ver a categoria da linguagem ocupar todo o lugar" (p. 143). Ora, se pensarmos a linguagem como uma dimensão da experiência com fundamentos pré-reflexivos, ela não pode ocupar todo lugar, não pode ser concebida como particular ou pertencente ao sujeito, mas articulada ao entrelaçamento entre corporeidade, mundo, sentido e tempo. Desta perspectiva, a linguagem não pode ser circunscrita como a tradução de um pensamento, nem o sujeito falante como tradutor dos objetos do mundo. Não diz respeito, portanto, ao reduto das significações, ou uma ferramenta privilegiada para acessar o sentido - a linguagem enquanto dimensão da experiência não pode ser concebida como um instrumento pronto para ser usado ou constituir o sujeito ${ }^{24}$.

Mas a linguagem não está no mundo antes do sujeito? Neste âmbito, Merleau-Ponty (1960/1991) concebe uma espécie de dialética entre a sedimentação e a inovação, pois ela é anterior à fala, mas só existe paradoxalmente porque é recriada constantemente pela fala. Logo, diferente da posição de um linguista, o esforço é de circunscrever a linguagem da perspectiva do sujeito falante.

Em concordância com a noção diacrítica da linguagem de Saussure, Merleau-Ponty (1960/1991) indica que os vocábulos da linguagem considerados separadamente não possuem um sentido em si, mas o sentido surge no ato de fala. Destaca-se, portanto, a língua falada ou viva e o seu valor expressivo que não se reduz à soma dos valores expressivos pertencentes a cada elemento da cadeia verbal (Merleau-Ponty, 1960/1991). O filósofo enfatiza, portanto, a linguagem no ato da expressão como passível de exprimir "alguma coisa que nunca haviam dito" (MerleauPonty, 1960/1991, p. 80). Logo, a questão da linguagem reside menos nas palavras que foram ditas ou nos sentidos que elas produzem e mais na possibilidade de articular uma experiência que, conforme destacamos anteriormente, engendra de maneira infalível corporeidade, mundo, tempo e sentido. O sentido, portanto, não reside naquilo que foi dito, isto é, no significado das palavras,

Não está na frase como manteiga na fatia de pão, qual segunda camada de "realidade psíquica" estendida por cima do som: o sentido é a totalidade do que se diz, a integral de todas as diferenciações da cadeia verbal, é dado com as palavras aos que possuem ouvidos para ouvir (Merleau-Ponty, 1964/2014, p. 152).

Deste modo, mais do que as palavras e seus significados, a fala guarda algo de uma experiência sensível. É possível afirmar, conforme destacado anteriormente, que quando nos confrontamos com um romance genuíno, um poema, uma pintura ou um filme, sabemos que esse contato se estabeleceu com alguma coisa, algum lampejo de sentido. No entanto, conforme aponta Merleau-Ponty (1960), o significado do trabalho para o artista ou para o público não pode ser declarado, exceto pelo trabalho mesmo: nem o pensamento que o criou, nem o pensamento que o recebe são os donos desta experiência. São, portanto, os atos de expressão autêntica que aproximam o escritor do pintor, do filósofo - uma espécie de abertura que condiciona tanto a primeira fala da criança como a fala do escritor, a construção do vocábulo como a do conceito.

Não gratuitamente no ensaio sobre a linguagem ( A linguagem indireta e as vozes do silêncio, MerleauPonty, 1960/1991) que foi revisitado em grande parte no livro póstumo A prosa do mundo (1969/2002),

\footnotetext{
${ }^{23}$ Esta questão está intimamente articulada à problemática do inconsciente. Merleau-Ponty (1964/2014) procura destacar uma noção de inconsciente que não se articula às representações na sua última obra. Para um maior aprofundamento na problemática do inconsciente na psicanálise em articulação à filosofia de Merleau-Ponty, ver Coelho (1991).

${ }^{24}$ Posto que, nas suas primeiras obras, Merleau-Ponty recorra à noção de estrutura para tematizar a questão da linguagem, esta não é totalmente congruente com o aspecto que o filósofo destacou, e que nós queremos enfatizar, a saber: o confronto entre o que podemos o aspecto sedimentado e a possibilidade de mudança ou transformação da linguagem no sujeito falante.
} 
Merleau-Ponty recorre à linguagem da pintura, à do pintor como meio de tornar mais evidente suas próprias concepções sobre a linguagem verbal e escrita. É a possibilidade do ato de fala (ou de expressão) que é capaz de tocar algo do silêncio - nesse sentido, pode-se afirmar que "toda linguagem é direta ou alusiva e, se quisermos, silêncio" (p. 54). Em uma direção parecida, o pianista alemão Arthur Schnabel costumava dizer: "as notas, eu não as toco melhor do que muitos outros pianistas. Mas as pausas... nelas é que reside a arte" (Naffah Neto \& Gerber, 2007, p. 10). Ora, mas o que essa espécie de divagação sobre a fala e o silêncio pode nos tocar enquanto analistas?

Ogden (2005) inicia um texto sobre a linguagem na psicanálise, chamando atenção para a importância da vitalidade no uso da linguagem, isto é, para sua possibilidade expressiva que não se encerra no significado das palavras. Assim como Merleau-Ponty ${ }^{25}$, Ogden (2005) enfatiza o ato de expressão através da linguagem articulando com a literatura na qual, conforme comentamos acima, "a experiência humana não está apenas sendo descrita, mas está sendo criada no efeito produzido pelo escritor sobre o leitor" (p.34). Neste âmbito, enquanto analistas, é preciso estar atento não para o que a linguagem expressa, não para o sentido escondido ou atrás das palavras $^{26}$, mas para os efeitos criados por ela-pela possibilidade de constituir uma dimensão da experiência.

Conforme destacamos anteriormente, a experiência não pode ser entendida como algo subjetivo ou particular. Deste olhar, em uma sessão analítica não se trata de escutar ou perscrutar o que o paciente está dizendo, mas também o modo pelo qual diz e, principalmente, "o efeito criado com isso pelo paciente na relação analítica, em um determinado momento." (Ogden, 2005, p. 214) ${ }^{27}$. Neste âmbito, não só a fala do paciente, mas também a do analista devem ser enfatizadas na sua capacidade de criar possibilidades e não apenas na função de criar compreensões ou insights. A partir da discussão de um caso clínico, Ogden (2005) indica que certas vezes não se trata de compreender através da linguagem o que o paciente está falando sobre o que pensa, sente, percebe ou experimenta no seu corpo, mas de "criar um efeito na linguagem: a experiência de envolver si mesmo na pura sensação dos sons das palavras" (p. 228).

Logo, o uso da linguagem na psicanálise pode ser concebido através da possibilidade tanto do analista ${ }^{28}$, quanto do analisando de criar a linguagem "com sua própria voz" (Ogden, 2005, p. 224). Esta possibilidade expressiva inclui não apenas o que foi dito, mas principalmente o modo como foi dito (o ritmo, a entonação, a cadência), tornando-se central como um "meio de comunicação das experiências inconscientes no setting analítico" (Ogden, 2005, p. 225). Ora, relembrando que para Winnicott a análise diz respeito, sobretudo, à possibilidade de experienciar - de que adianta poder falar sem que o que se fala ou a maneira que se fala articule-se a uma experiência? Trata-se, portanto, de enfatizar os efeitos criados pela linguagem, ou mesmo da possibilidade de criar a linguagem - assim como fazem certos escritores, filósofos, artistas e, por que não, o setting analítico? Em uma carta a Guimarães Rosa, Manuel Bandeira (1967) escreve: "Ao despois de depois, andaram dizendo que você tinha inventado uma língua nova e eu não gosto de língua inventada. Sempre arreneguei de esperantos e volapuques. Vai-se ver, não é língua nova nenhuma a do Riobaldo. Difícil é, às vezes. Quanta palavra do sertão!" (p. 591). O sertão, no entanto, não é um lugar, não é o homem, o "sertão é isto: o senhor empurra para trás, mas de repente ele volta a rodear o senhor dos lados. Sertão é quando menos se espera." (Guimarães Rosa, 2001, p. 249). Na esteira do comentário de Manuel Bandeira, não se trata, portanto, de criar uma língua nova, com certa gramática ou novas palavras, mas da possibilidade de o uso da linguagem tocar algo da dimensão de uma experiência sensível.

Portanto, é preciso, no campo da psicanálise, destacar esta dimensão da linguagem que não se restringe à linguagem dos linguistas e que também não está em toda parte, mas que toca algo da experiência articulada ao entrelaçamento entre corporeidade, tempo, mundo e sentido. Talvez assim a linguagem possa ser discutida no campo psicanalítico a partir da sua vitalidade e de seu uso, abrindo caminhos para diferentes questões teórico-clínicas.

\footnotetext{
${ }^{25}$ Em um artigo bastante interessante, Reis (1999) aproxima as concepções de Ogden à filosofia de Merleau-Ponty, destacando, entre outras questões, a problemática da linguagem.

${ }^{26}$ É justamente nesse sentido que se pode discutir uma concepção de inconsciente que não está escondido nas palavras.

${ }^{27}$ Mais do que na relação analítica aqui seria importante mais uma vez remeter à noção de terceiro analítico (Ogden, 1994).

${ }^{28}$ Ogden (2005) chama atenção para certos modos de expressão estereotipados dos analistas, muitas vezes permeados por uma espécie de cacoete provindo do engessamento provocado pela forte adesão a escolas específicas.
} 


\section{Referências}

Angelino, L. (2005). Merleau-Ponty/Melanie Klein: proposta di un confront. Segni e Compreensione, 56, 124-131.

Bandeira, M. (1967). Grande Sertão:Veredas. In M. Bandeira, Poesia completa e prosa (pp. 590-592). Rio de Janeiro, RJ: Aguilar.

Bezerra, B., Jr. (2001). O lugar do corpo na experiência do sentido: uma perspectiva pragmática. In B. Bezerra Jr. \& C. A. Plastino (Orgs.), Corpo, afeto, linguagem. A questão do sentido hoje (pp. 13-42). Rio de Janeiro, RJ: Marca d’Água.

Bezerra, B., Jr. (2008). A noção de experiência e sua importância para a clínica atual. In A. Arruda, B. Bezerra Jr., \& S. Tedesco (Orgs.), Pragmatismos, pragmáticas e produção de subjetividades (pp. 221-224). Rio de Janeiro, RJ: Garamond.

Coelho, N. Jr. (1991). O inconsciente em Merleau-Ponty. In F. Knobloch (Org.), O inconsciente: várias leituras (pp. 123-146). São Paulo, SP: Escuta.

Coelho, N., Jr., \& Barone, K. (2007). A importância da teoria de Winnicott sobre a comunicação para a construção do significado ético da psicanálise. Revista Brasileira de Psicanálise, 41(3), 88-100.

Coelho, N., Jr. (2010). Da intercorporeidade à co-corporeidade. Elementos para uma clínica psicanalítica. Revista Brasileira de Psicanálise, 44(1), 51-60.

Coelho, N. E. Jr, Figueiredo, L. C. "Figuras da Intersubjetividade na constituição subjetiva: dimensões da alteridade". In: Coelho, N. Jr., Salem, P. \& Klautau, P. (2012) Dimensões da Intersubjetividade. São Paulo FAPESP/Escuta, pp. 19-35

Costa, J. F. (2001). A questão do sentido em psicanálise. In B. Bezerra Jr. \& C. A. Plastino (Orgs.), Corpo, afeto, linguagem: a questão do sentido hoje (pp. 199-218). Rio de Janeiro, RJ: Marca d’Água.

David-Ménard, M. (2000). Tout le plasir est pour moi. Paris: Hachett et Littératures.

Ey, H. (Org.). (1966). L’ Inconscient. VIe. Colloque de Bonneval. Paris: Desclée de Brouwer.

Freud, S. (1977). Projeto para uma psicologia científica. In Edição standard brasileira das obras psicológicas completas de Sigmund Freud (J. Salomão, Trad., Vol. 1, pp. 381-456). Rio de Janeiro, SP: Imago. (Trabalho original publicado em [1895]1950)

Gabbi, O. (2005). Sonhos, pensamentos, palavras. In L. Fulgêncio \& R. Simanke (Orgs.), Freud na filosofia brasileira (pp. 169-202). São Paulo, SP: Escuta.

Green, A. (1964). Du compartament a la chair: itinanéraire de Merleau-Ponty. Critique, 211, 1017-1047.

Green, A. (1984). Le langage dans la psychanalyse. In A. Green (Org.), Langages. II Recontres psychanalytiques d'Aix -en-Provance (1983) (pp. 19-250). Paris: Société d'Édition Les Belles Lettres.

Gomes, S. (2017). A gramática do silêncio em Winnicott. São Paulo, SP: Zagodoni.

Guimarães Rosa, J. (1954). Corpo de baile. Rio de Janeiro, RJ: José Olympio.

Guimarães Rosa, J. (2006). Grande sertão: veredas. Rio de Janeiro, RJ: Nova Fronteira.

Isaacs, S. (1998). Comunicação de Susan Isaacs sobre "Natureza e função da fantasia". In P. King \& R. Steiner (Orgs.), As controvérsias entre Freud-Klein (1941-45) (pp. 275-328). Rio de Janeiro: Imago. (Trabalho original proferido em 1943)

Lannes, E. (1997). A continuidade de ser. Cadernos de Psicanálise, 11, 94-98.

Macckay, I. (1981). Melanie Klein's methapsychology: phenomenological and mechanistic perspective. International Journal of Psycho-Analysis, 62,187-198.

Merleau-Ponty, M. (1975). A estrutura do comportamento (J. Corrêa, Trad.). Belo Horizonte, MG: Interlivros. (Trabalho original publicado em 1942)

Merleau-Ponty, M. (1991). Signos (M. Pereira, Trad.). São Paulo, SP: Martins Fontes. (Trabalho original publicado em 1960)

Merleau-Ponty, M. (1996). Sens et non-sens. Paris: Gallimard. (Trabalho original publicado em 1948)

Merleau-Ponty, M. (2002). A prosa do mundo (P. Neves, Trad.). São Paulo, SP: Cosac \& Naify. (Trabalho original publicado em 1969)

Merleau-Ponty, M. (2011). Fenomenologia da percepção (C. Moura, Trad.). São Paulo, SP: Martins Fontes. (Trabalho original publicado em 1945) 
Merleau-Ponty, M. (2014). O visível e o invisível. São Paulo, SP: Perspectiva. (Trabalho original publicado em 1964)

Naffah Neto, A (2005). Winnicott: uma psicanálise da experiência humana em seu devir próprio. Natureza Humana, $7(2), 433-454$.

Naffah Neto, A., \& Gerber, I. (2007). Linguagem musical e psicanálise. Ide (São Paulo), 30(44), 8-14.

Ogden, T. (1989). The primitive edge of experience. New Jersey: Jason Aronson.

Ogden, T. (1994). Subjects of analysis. Northvale: Jason Aronson.

Ogden, T. (1999). On the use of language in psychoanalysis. In T. Ogden, Reverie and interpretation: sensing something human (pp. 107-133). London: Karnac.

Ogden, T. (2005). This Art of Psychoanalysis: Dreaming Undreamt Dreams and Interrupted Cries. London: Routledge.

Ogden, T. (2013). Reading Winnicott. In J. Abram (Ed.), Winnicott Today (pp. 56-68). New York: Routledge. (Trabalho original publicado em 2001)

Ogden, T. (2014). Lendo Susan Isaacs: para uma revisão radical da teoria do pensar. In T. Ogden, Leituras criativas (pp. 61-88). São Paulo, SP: Escuta.

Petot, J. M. (1988). Melanie Klein II: O ego e o bom objeto - 1932-1960. São Paulo, SP: Perspectiva.

Reis, B. (1999). Thomas Ogden's phenomenological turn. Psychoanalytic Dialogues, 9(3), 371-393.

Rosa, J.G. (2001) Grande Sertão: Veredas. 19a edição. Rio de Janeiro: Nova Fronteira.

Simanke, R. T. (2005). Memória, afeto e representação: o lugar do projeto no desenvolvimento inicial da metapsicologia freudiana. Olhar, 13, 12-40.

Simanke, R. (2016). Identidade, significação e intercorporeidade na obra inicial de Freud. Palavras: Revista de Epsitemología, Metodología y Ética del Psicoanálisis, 2, 87-119.

Souza, O. (2000). Aspectos do encaminhamento da questão da cientificidade da psicanálise no movimento psicanalítico. In R. A. Pacheco Filho, N. Coelho Junior, \& M. Rosa (Orgs.), Ciência, pesquisa, representação e realidade em psicanálise (pp. 3-20). São Paulo, SP: Editora Casa do Psicólogo.

Verztman, J., \& Klein, T. (2017). Desarrollo y la temporalidad en la obra de Winnicott: de la ruta al proceso. Intersubjetivo. Revista de Psicoterapia Psicoanalítica y Salud, 16, 82-98.

Winnicott, D. (1988). Creativity and its origins. In D. Winnicott, Playing and reality (pp. 66-75). Londres: Pelican books. (Trabalho original publicado em 1971)

Winnicott, D. (2005). O gesto espontâneo (2a ed.). São Paulo, PS: Martins Fontes. (Trabalho original publicado em 1952).

\section{Thais Klein}

Psicanalista; doutora em Teoria Psicanalítica pelo Programa dePós-Graduação em Teoria Psicanalítica da Universidade Federal do Rio de Janeiro e doutora em Saúde Coletiva pelo Instituto de Medicina Social da Universidade Estadual do Rio de Janeiro (IMS-UERJ). Membro do Núcleo de Estudos em Psicanálise e Clínica da Contemporaneidade (Nepecc). Professora auxiliar do Centro Universitário Augusto Motta (Unisuam), Rio de Janeiro - RJ. Brasil.

E-mail: thaiskda@gmail.com

(1) https://orcid.org/0000-0002-5050-9855

\section{Julio Verztman}

Professor do Programa de Pós-Graduação em Teoria Psicanalítica do Instituto de Psicologia da Universidade Federal do Rio de Janeiro. Coordenador do Núcleo de Estudos em Psicanálise e Clínica da Contemporaneidade (Nepecc). psiquiatra do Ipub-UFRJ, Rio de Janeiro - RJ. Brasil.

E-mail: jverztman@globo.com

(1) https://orcid.org/0000-0001-5495-3737 


\section{Nelson Ernesto Coelho Junior}

Psicanalista. Professor e pesquisador do Instituto de Psicologia da Universidade de São Paulo (IP-USP), São Paulo-SP.

Brasil.

E-mail: ncoelho@usp.br

(1) https://orcid.org/0000-0002-0707-7356

Endereço para envio de correspondência:

Rua Tonelero 162/4, Copacabana. CEP: 22030-002. Rio de Janeiro - RJ. Brasil.

Recebido 27/12/2017

Aceito 28/01/2019

Received 27/12/2017

Approved 28/01/2019

Recibido 27/12/2017

Aceptado 28/01/2019

Como citar: Klein, T., Vertzman, J., \& Coelho Junior, N. (2020). A Linguagem como Experiência: Diálogos entre Merleau-Ponty e a Psicanálise Psicologia: Ciência e Profissão, 40, 1-14.

https://doi.org/10.1590/1982-3703003189598

How to cite: Klein, T., Vertzman, J., \& Coelho Junior, N. (2020). Language as Experience: Dialogues between Merleau-Ponty and Psychoanalysis. Psicologia: Ciência e Profissão, 40, 1-14.

https://doi.org/10.1590/1982-3703003189598

Cómo citar: Klein, T., Vertzman, J., \& Coelho Junior, N. (2020). El Lenguaje como Experiencia: Diálogos entre Merleau-Ponty y el Psicoanálisis. Psicologia: Ciência e Profissão, 40, 1-14.

https://doi.org/10.1590/1982-3703003189598 